many of the questions to be answered will have been predefined, together with the clinical core datasets. The Royal College of Radiologists will own the summary data and control access to them. Clinical oncologists will be able to study the outcome of comparative analyses before publication and to determine measures to complete the audit cycle. Education and the achievement of quality, rather than coercion and censure, are the goals of the network.

S J KARP

North Middlesex Hospital,

Consultant clinical oncologist

London N18 1QX
1 Tobias J. What went wrong at Exeter? BMF 1988;297:372-3.

2 North Staffordshire Health Authority. Report of the independent clinical assessment on the effects of the radiation incident at the North Staffordshire Royal Infimary. Stoke-on-Trent: North Staffordshire Health Authority, 1993

3 Sikora K. Enraged with radiotherapy. BMF 1994;308:188.

4 Dyer C. Manslaughter convictions for making mistakes. BM于 1991;303:1218.

5 Ryall RDII. Setting a standard. Clinical Oncology 1993;5:129-30.

8 Basnett I, Gill M, Tobias JS. Variations in breast cancer management between a teaching and a non-teaching district. Eur f Cancer 1992;28A:1945-50.

7 Gulliford MC, Petruckevitch A, Burney PGJ. Survival with bladder cancer, evaluation of delay in treatment, type of surgeon, and modality of treatment. $B M \mathcal{F} 1991 ; 303: 437-40$.

8 Chouillet AM, Bell CMJ, Hiscox JG. Management of breast cancer in southeast England. BM 1994;308:168-70.

9 Gulliford MC, Bell J, Bourne HM, Petruckevitch A. The reliability of cancer registry records. $\mathrm{Br} \mathfrak{Y}$ Cancer 1993;67:919-21.

10 NHS IMG. Information management in the hospital and community health services: minimum data set model version 3.0. Birmingham: NHS IMG, 1993.

\title{
Multidrug resistance in cancer
}

\section{Identification of the genetic basis of resistance is opening up new prospects for chemotherapy}

Malignant neoplasms vary in their response to cytotoxic drugs: some are sensitive, others resistant. Understanding of the biochemical basis of this resistance might lead to the development of markers that would correlate with the clinical response to the drugs - or even lead to ways of overcoming the resistance.

Multidrug resistance was first described in 1970 after selection of Chinese hamster ovarian cancer cells exposed to increasing concentrations of actinomycin D. ${ }^{1}$ Though the cells had been selected by a single agent, they proved to be resistant to a range of clinically important anticancer drugs, including the anthracyclines (doxorubicin and daunomycin), the vinca alkaloids (vincristine, vinblastine, and vindesine), etoposide, and colchicine. Riordan and Ling went on to show that the multidrug resistant cells had lower concentrations of the drug - a drug accumulation deficit - and that a membrane glycoprotein of $170 \mathrm{kDa}$ was responsible. ${ }^{2}$ At first the deficit was thought to be due to a fault in permeation and the glycoprotein was named P glycoprotein (P-gp). ${ }^{3}$ The gene for this, mdr-1, has been cloned and sequenced, and the amino acid has been sequenced and the amino acid sequence derived. ${ }^{4} \mathrm{P}$ glycoprotein has 1280 amino acids, and its structure suggests that it arose from the fusion of two closely related genes; it uses ATP as a source of energy. The precise molecular mechanism whereby $\mathbf{P}$ glycoprotein can transport such a wide range of structurally diverse drugs is uncertain, and several models have been proposed.5-7

$\mathbf{P}$ glycoprotein belongs to a superfamily of ATP binding cassette transporters, whose members include the cystic fibrosis transmembrane regulator, the chloroquine transporter of Plasmodium falciparum, and a yeast transporter. ${ }^{8}$ Recently a new member of this family was cloned from a human small cell lung cancer cell line, H69AR. Though it was resistant to doxorubicin and vincristine, it did not express $P$ glycoprotein. ${ }^{9}$ This protein has 1522 amino acids and has been termed multidrug resistance associated protein (MRP). Cells with this type of resistance may not have accumulation deficits of doxorubicin. One possible explanation is that multidrug resistance associated protein facilitates the sequestration of cytotoxic drugs into intracellular organelles. ${ }^{9}$ Whether this protein binds to the drugs against which it confers resistance is not known, but the emergence of a potential new target for modulation, if it is widely expressed in human tumours, is clearly an exciting development.

Several probes have been developed that can detect the $P$ glycoprotein gene, its mRNA, and its protein product. ${ }^{1011}$
Studies have shown that the gene expressed in normal gastrointestinal mucosal cells, renal tubular cells, biliary canalicular cells, and adrenocortical cells. ${ }^{11}$ Tumours that are initially sensitive to chemotherapy but resistant on relapse commonly show increases in expression of $\mathbf{P}$ glycoprotein. Leukaemias with high concentrations of $\mathbf{P}$ glycoprotein tend to be resistant to inductive treatment with chemotherapy based on anthracycline. ${ }^{12}$ Expression of $\mathbf{P}$ glycoprotein is an adverse factor in multivariate prognostic models for childhood sarcoma and neuroblastoma. ${ }^{1314}$ Before long it may be practicable to "tissue type" tumours according to expression of $\mathbf{P}$ glycoprotein and, perhaps, to avoid the toxicity and reduced quality of life associated with treatment with ineffective anticancer drugs.

After an initial observation by Tsuruo et al, ${ }^{15}$ several groups have shown that transport defect mediated by $\mathbf{P}$ glycoprotein can be blocked by many non-cytotoxic drugs, including nifedipine, verapamil, quinine, chloroquine, progestogens, tamoxifen, cyclosporin $\mathrm{A}$ and its analogues, reserpine and tricyclic anti-depressants. ${ }^{16}$ Clinical trials have assessed the combination of conventional chemotherapy with modulators of P glycoprotein; in one study of relapsed non-Hodgkin's lymphoma 13 of 18 patients responded to infusional chemotherapy with high doses of verapamil. ${ }^{17}$ Unfortunately, the amounts of verapamil needed to reverse drug resistance produced congestive cardiac failure and heart block. Research groups are currently looking for potent, non-toxic modulators of $\mathrm{P}$ glycoprotein to combine with conventional chemotherapy. Cyclosporin A has been reported to reverse clinical multidrug resistance in myeloma. ${ }^{18}$ The combination of quinidine with the antineoplastic agent epirubicin was recently assessed in a prospective, placebo controlled randomised study in patients with advanced breast cancer. ${ }^{19}$ Tumour response rates and survival were similar in the two arms of the trial, a finding that probably reflects the low potency of quinidine to bind $\mathrm{P}$ glycoprotein. ${ }^{\text {? }}$

Another possible application of the genetics of $\mathbf{P}$ glycoprotein is in gene therapy. Transgenic mice that express human $\mathbf{P}$ glycoprotein in their bone marrow are resistant to chemotherapy, ${ }^{20}$ so in theory if human bone marrow could be transfected with the gene that might protect it against myelosuppression from anticancer chemotherapy. ${ }^{8}$

Novel, improved modulators of $\mathrm{P}$ glycoprotein seem likely to be developed in parallel with mechanistic research on the function of the gene, and thus should lead to the rational design of inhibitor. Future phase II clinical trials with new 
modulators of $\mathbf{P}$ glycoprotein must include pharmacokinetic studies since interactions can occur with cytotoxic drugsfor example, etoposide's activity is increased by $80 \%$ when it is given in combination with cyclosporin A. ${ }^{21}$ These trials should focus on those cancers that are known to express high concentrations of $\mathrm{P}$ glycoprotein (including renal and colorectal cancers and sarcomas). Since $P$ glycoprotein is expressed in normal tissues there is some concern that its modulators might alter the cellular transport of physiological metabolites such as bilirubin and thereby delay the clearance of cytotoxic drugs that undergo hepatobiliary excretion. These clinical trials should therefore be performed in units used to handling the toxicity associated with intensive chemotherapy.

DAVID R FERRY

Senior registrar in medical oncology

DAVID J KERR

Professor of clinical oncology

CRC Department of Clinical Oncology,

Clinical Research Block,

Queen Elizabeth Hospital,

Birmingham B15 2TH

1 Bielder $\mathrm{J}$, Reiehm $\mathrm{H}$. Cellular resistance to Chinese hamster cells in vitro: cross resistance, radioautographic studies and cytogenetic studies. Cancer Res 1970;30:1174-84.

2 Riordan JR, Ling V. Purification of P-glycoprotein from plasma membranes vesicles of Chinese hamster ovary cell mutants with reduced colchine permeability. $¥$ Biol Chem 1979;254:12701-5.

Carlsen SA, Till JE, Ling V. Modulation of membrane drug permeability in Chinese hamster ovary cells. Biochem Biophy Acta 1979;455:900-12.

4 Gros P, Croop J, Housman D. Mammalian multidrug resistance gene: complete cDNA sequence indicates a strong hormology to bacterial transport proteins. Cell 1986;46:371-80.
5 Raviv Y, Pollard HB, Bruggemann EP, Pastan I, Gottesman MM. Photosensitised labelling of a functional multidrug transporter in living drug resistant tumour cells. $f$ Biol Chem 1990;265: 3975-80.

Higgins CF, Gottesman MM. Is the multidrug resistance transporter a flippase? Trends Biochem Sci 1992;17:18-21.

7 Ferry DR, Russell M, Cullen MH. P-glycoprotein possesses a 1,4-dihydropyridine-selective drug acceptor site which is allosterically couple to a vinca-alkaloid-selective binding site. Biochem Biophys Res Commun 1992;188:440-5.

8 Gottesman MM, Pastan I. Biochemistry of multidrug resistance mediated by the multidrug transporter. Annu Rev Biochem 1993;62:385-427.

9 Cole SPC, Bhardwaj G, Gerlach JH, Mackie JE, Grant CE, Almquist AJ, et al. Overexpression of a transporter in a multidrug-resistant human lung cancer cell line. Science 1992;258:1650-4.

10 Fojo AT, Ueda K, Salmon DJ, Poplack DG, Gottesman MM, Pastan I. Expression of a multidrug resistance gene in human tumors and tissues. Proc Natl Acad Sci USA 1989;84:265-9.

11 Cordon-Cardo C, O'Brien J, Casals C, Boccia J, Bertino JR. Immunoanatomical and immunopathological expression of the multidrug-resistance gene product. Cancer Cells 1989;7:87-93.

12 Kuwaturu Y, Yoshimura A, Hanade S, Utsunomiya A, Makino T, Ishibashi K, et al. Expression of the multidrug transporter, P-glycoprotein in acute leukaemia cells and correlation to clinical drug resistance. Cancer 1990;66:868-73.

13 Chan HLS, Thorner PS, Haddad G, Ling V. Immunohistochemical detection of P-glycoprotein prognostic correlation in soft tissue sarcoma of childhood. $f$ Clin Oncol 1990;8:689-704.

14 Chan HLS, Haddad G, Thorner PS, DeBoer G, Lin YP, Ondrusek N, et al. P-glycoprotein as a predictor of outcome of therapy for neuroblastoma. N Engl ₹ Med 1991;325:1608-14.

15 Tsuruo T, Iida H, Kitatani Y, Yokota K, Tsukagoshi S, Sakurai Y. Effects of quinidine and related compounds on cytotoxicity and cellular accumulation of vincristine and adriamycin in drug resistant tumour cells. Cancer Res 1984;44:4303-7.

16 Endicott JA, Ling V. The biochemistry of P-glycoprotein-mediated multidrug resistance. Annu Rev Biochem 1989;58:137-71.

17 Miller TP, Grogan TM, Dalton WS, Spier CM, Scheper RJ, Salmon SE. P-glycoprotein expression in malignant lymphoma and reversal of clinical drug resistance with chemotherapy plus high dose verapamil. C Clin Oncol 1991;9:17-24.

18 Sonneveld P, Durie BGM, Lokhorst HM, Marie J-P, Solbu G, Suciu S, et al. Modulation of multidrug resistant multiple myeloma by cyclosporin. Lancet 1992;340:255-9.

19 Wishart GC, Harnett C, Kerr DJ, Paul J, Machem MA, Soukup M, Leonard RCF, Kaye SB. A randomised placebo controlled trial of quinidine as a resistance modulator in patients with advanced breast cancer treated with epirubin [abstract]. Proceeding of American Society of Clinical Oncology 1993;12:33.

20 Mickisch GH, Merlino GT, Galski H, Gottesman MM. Transgenic mice that express the human multidrug-resistance gene in bone marrow enable a rapid identification of agents that reverse drug resistance. Proc Natl Acad Sci USA 1991;88:547-51.

21 Lum BL, Kanbish S, Yahanda AM, Adler KM, Jew L, Ehsan NM, et al. Alteration of etoposide pharmacokinetics and pharmacodynamics by cyclosponine in a phase I trial to modulate multidrug resistance. $f$ Clin Oncol 1992;10:1635-42.

\section{Human parvovirus B19}

\section{The cause of an illness with an erythematous rash and a possible problem in pregnancy}

Infection with parvovirus B19 is most common in children between the ages of 4 and 11. About half the infections are asymptomatic, and many of the remainder cause a nonspecific illness of the respiratory tract. ${ }^{1}$ The most common distinct disease associated with the infection is erythema infectiosum-also known as fifth disease or slapped cheek disease. ${ }^{2}$ Erythema infectiosum is usually diagnosed clinically only when there is an outbreak of illness with a rash in young children and red cheeks are a prominent feature. Illness with an erythematous rash due to parvovirus B19 infection is worldwide and common, but in the absence of laboratory tests it is often diagnosed as rubella (both rubella and parvovirus B19 infection have a similar seasonality), allergy, or simply a "viral infection."

An arthropathy similar to that seen in rubella may be associated with parvovirus B19 infection. The most common pattern is symmetric arthralgia or arthritis in the small joints of the hands, with the wrists, knees, and ankles affected in some cases. Joint symptoms occur in only $10 \%$ of children with the infection but in as many as $80 \%$ of adult women. The symptoms and signs of the joint disorder usually resolve within two weeks, but they may persist for months and occasionally for years. ${ }^{34}$

The diseases described above occur in normal people. In those with some underlying haemolytic state-such as sickle cell anaemia or hereditary spherocytosis-parvovirus B19 infection is associated with a transient acute worsening of the anaemia. This aplastic crisis results from a halt in erythropoiesis in the bone marrow for five to seven days - the patients have a normal immune system and clear the virus in the usual way. ${ }^{5}$ By contrast, parvovirus B19 infection in patients with some immunodeficiency states (Nezelof's syndrome, acute lymphatic leukaemia, and HIV infection) is usually chronic and associated with persistent or remitting and relapsing anaemia. ${ }^{67}$ The bone marrow is typical of that seen in aplastic crises complicating haemolytic anaemias; the underlying cause is the weak humoral immune response in these patients. Administration of human immunoglobulin will result in transient or permanent clearance of the virus and improvement of the anaemia.

Because of the similarity between the rashes in illnesses due to parvovirus B19 infection and rubella and the occurrence of fetal damage in parvovirus infections in animals, an adverse effect of parvovirus B19 infection might be expected in pregnancy. Early studies suggested that the spontaneous abortion rate was increased. There has been one systematic study in Britain of the outcome of pregnancies complicated by parvovirus B19 infection confirmed in a laboratory. ${ }^{8}$ This showed no increase in the number of spontaneous abortions in the first trimester, but 1 in 10 of the pregnancies ended in spontaneous abortion during the second trimester-10 times the expected rate. In the cases in which the mother had clear cut symptoms the pregnancy was lost on average four to six weeks after the onset of the maternal illness.

Many studies in Europe and the United States have shown that hydrops fetalis sometimes occurs as a consequence of infection with parvovirus B19 virus in the second or third trimester..$^{9}$ The hydrops may be transient or ultimately fatal and is consistently associated with anaemia and sometimes with myocarditis in the fetus. Whether intrauterine parvo- 